\title{
Design of a continuously and linearly controlled VSI-based STATCOM for load current balancing purposes
}

\author{
Faris Asaad Abdulmunem ${ }^{1}$, Abdulkareem Mokif Obais ${ }^{2}$ \\ ${ }^{1}$ Department of Electrical Engineering, University of Babylon, Babylon, Iraq \\ ${ }^{2}$ Department of Biomedical Engineering, University of Babylon, Babylon, Iraq
}

\begin{tabular}{l} 
Article Info \\
\hline Article history: \\
Received Sep 24, 2020 \\
Revised Jan 19, 2021 \\
Accepted Feb 7, 2021 \\
\hline Keywords: \\
Load compensation \\
Power factor correction \\
Power quality \\
Reactive power control \\
STATCOMs
\end{tabular}

STATCOMs

\begin{abstract}
In this paper, load current balancing are reviewed in both three-wire and 4wire systems taking into account linearity, harmonics injection, and control schemes. A linearized static compensator (STATCOM) based on H-bridge voltage source inverter (VSI). The proposed STATCOM is controlled in closed loop mode via equipping it with a new current controller. The DC capacitor voltage of the STATCOM is kept constant without using external energy injection or storage devices via shunting the DC capacitor with a suitable series filter. The simulation results of the current responses of the $220 \mathrm{~V}, 50 \mathrm{~Hz}$ STATCOM reveal continuous and linear performance during responding to reactive current demands from $123 \mathrm{~A}$ inductive current to $227 \mathrm{~A}$ capacitive current. The transition time required for the proposed STATCOM during treatment of a sudden change in reactive current demand from maximum inductive current to maximum capacitive current is less than $40 \mathrm{~ms}$. The steady state portions of the STATCOM current responses show pure sinusoids, thus the proposed STATCOM can be promoted as harmonic free static Var compensator. The closed loop continuous mode control and the considerable linearity of the proposed STATCOM promot it as a bipolar susceptance (capacitive and inductive) in applications of load current balancing systems in both three and four wire power systems.
\end{abstract}

This is an open access article under the CC BY-SA license.

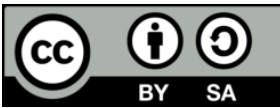

\section{Corresponding Author:}

Abdulkareem Mokif Obais

Departement of Biomedical Engineering

University of Babylon

Hilla, Babylon, Iraq

Email: karimobais@yahoo.com

\section{INTRODUCTION}

In 1981, an advanced static Var compensator in prototype form was introduced by [1]. The compensator was built using force-commutated inverters. This prototype founded a basis for STATCOM concept. The rapid increasing in the switching frequencies of the solid-state switching devices beside the development in multilevel technologies makes it possible to apply pulse width modulation (PWM) techniques in the STATCOMs designed for high power applications. The control scheme of a PWM-based STATCOM was investigated by [2]. During the model implementation of the controller, the STATCOM was modeled in the discrete time domain. An eight-level reinjection converter based STATCOM was proposed by [3] to provide very low distortion levels compared to a similar configuration using clamping diodes, even though the numbers of the main switching devices in both configurations were equal. STATCOMs are traditionally realized by voltage source converters, but for certain applications such as using a STATCOM as current injection device, current source converter based STATCOMs can introduce better performance [4]. The controlling strategies, harmonic analysis, operating points optimization, voltage unbalance mitigation, 
optimal modulation, modulation dynamic, real time analysis, transient response, and configuration layout of different STATCOMs were investigated in [5]-[7]. In [8], the H-bridge DC capacitors were charged initially in a proposed star-connected multilevel STATCOMs in order to guarantee the possibility of their equalization. In [9], a shunt active filter based on one-cycle control for load compensation of a three-phase four-wire system was investigated. In [10], a proposed controlling scheme for cascaded full bridge voltage source inverter (VSI) based STATCOM concentrated on individual balancing of the capacitor voltages of the full-bridge converters (H-bridge converters). The balancing process was carried out by comparing the instantaneous voltage of the H-bridge capacitor voltage with a reference one. A DSTATCOM devised from a low rating voltage source converter (VSC) and a zigzag transformer was introduced by [11] for improving the power quality of a three-phase four-wire distribution system. Voltage control, current control, and integrated control schemes were employed in a three-phase STATCOM for compensating unbalanced voltages and currents [12]. A $\Delta$-connected multilevel cascade converter based STATCOM was proposed by [13]. In the proposed STATCOM, the series reactors were connected in series to mutually coupled reactors. The mutually coupled reactors offered paths for circulating currents to flow.

In this research, a continuously and linearly controlled voltage source inverter (VSI) based fullbridge STATCOM is designed and tested. This STATCOM is characterized by high linearity and is harmonic free, thus it can considerably be exploited for load current balancing and energy saving purposes.

\section{THE PROPOSED LINEARIZED H-BRIDGE VSI BASED STATCOM}

A STATCOM in general is either a voltage source inverter (VSI) with its DC source replaced by a DC capacitor or current source inverter (CSI) with its DC source replaced by a DC reactor. Both categories of power converters exchange active power and reactive power with the AC source to some extents through small reactors. These definitions are applicable for both single and three-phase STATCOMs. Since STATCOMs can be employed in both active and reactive power applications, they are usually referred to as static compensators. The single-phase VSI-based STATCOM is shown in Figure 1. The STATCOM solidstate switching devices $Z_{1}, Z_{2}, Z_{3}$, and $Z_{4}$ are insulated-gate bipolar transistors (IGBTs) equipped with fast free-wheeling diodes. $v_{A C}$ and $V_{D C}$ represent the instantaneous voltage of the AC source and the DC capacitor voltage, respectively. The current $i_{S}$ represents the instantaneous STATCOM current. $L_{S T}$ and $R_{S T}$ are the selfinductance and resistance of the STATCOM reactor. The voltage $v_{i}$ represents the STATCOM or the VSI generated voltage. The STATCOM of Figure 1 is usually referred to as H-bridge STATCOM. Such STATCOMs are triggered by using sinusoidal pulse width modulation (SPWM) techniques. If $V_{D C}$ is kept constant and the STATCOM is triggered by the unipolar sinusoidal pulse width modulation (USPWM) shown in Figure 2, then $v_{i}$ will be given by

$$
v_{i}=\frac{V_{D C}}{5}\left(V_{Z 1}-V_{Z 3}\right)
$$

Where, $V_{Z 1}$ and $V_{Z 3}$ are the USPWM triggering signals of $Z_{1}$ and $Z_{3}$, respectively. $\beta$ is the STATCOM angle and it represents the phase shift of the modulating signal $v_{M O D}$ with respect to $v_{A C}$. $v_{T R I}$ is the carrier signal, which is a triangular waveform of amplitude of $V_{T R I}$ and frequency of $f_{C}$. Note that $v_{M O D}$ is a sinusoidal signal of amplitude $A_{M O D}$ and frequency $f$ which is the same frequency of the AC source $(f=\omega / 2 \pi)$. The term $\left(V_{Z 1}-V_{Z 3}\right)$ is positive when $v_{M O D}$ is positive and vice versa. The modulating signal $v_{M O D}$ can be defined as (2).

$$
v_{M O D}=V_{M O D} \sin (\omega t+\beta)
$$

For a STATCOM of a modulation index $m$, the average of $v_{i}$ within $v_{T R I}$ duration time $T_{C}$ is designated by $V_{i a v}$ and is determined by (3)

$$
V_{i a v}=\frac{1}{T_{C}} \int_{0}^{T_{C}} v_{i} d t^{\prime}=\frac{1}{T_{C}}\left(\int_{t^{\prime}{ }_{1}}^{t^{\prime}} V_{D C} d t^{\prime}+\int_{t^{\prime}{ }_{3}}^{t_{4}^{\prime}} V_{D C} d t^{\prime}\right)=m V_{D C} \sin (\omega t+\beta)
$$

The STATCOM modulation index $m$ is defined by (4)

$$
m=\frac{A_{M O D}}{A_{T R I}}
$$


To make (3) applicable over the carrier signal stream, the time $t$ is substituted by $k T_{C}$ and $\omega$ by $2 \pi / T$. Where, $T$ is the time duration of the modulating signal and $k=1,2,3$, and so on. Consequently, (3) can be rewritten as (5):

$$
V_{i a v}(k)=m V_{D C} \sin \left(\frac{2 \pi}{T} k T_{C}+\beta\right)=m V_{D C} \sin \left(\frac{2 \pi}{N} k+\beta\right)
$$

where, $N$ is defined by (6)

$$
N=\frac{T}{T_{C}}
$$

The variation of $V_{i a v}$ as function of $\omega t$ exhibits sinusoidal envelope and is in phase with $v_{M O D}$, thus it can be considered as the instantaneous fundamental component of voltage $v_{l}$ generated by the VSI, which can be expressed by (7)

$$
v_{1}=m V_{D C} \sin (\omega t+\beta)
$$

Assuming that the STATCOM reactor suppresses all current harmonics, the STATCOM rms fundamental current $I_{S}$ can be given as (8)

$$
I_{S}=\frac{V_{A . C}-V_{1} \angle \beta}{R_{S T}+j \omega L_{S T}}
$$

where, $V_{A C}$ is the rms voltage of the AC source and $V_{l}$ is the rms voltage of $v_{l} . V_{l}$ can be defined as (9)

$$
V_{1}=\frac{m V_{D C}}{\sqrt{2}}
$$

Assuming that $R_{S T}$ is negligible compared to $\omega L_{S T}$, (8) can be rewritten as (10)

$$
I_{S}=\frac{\left(V_{A C}-V_{1} \angle \beta\right)}{j \omega L_{S T}}
$$

If the angle $\beta$ is small and $V_{l}$ is greater than $V_{A C}, I_{S}$ will be to some extent pure capacitive, while it will be pure inductive if $V_{l}$ is less than $V_{A C}$. In general, small negative values of $\beta$ make $V_{l}$ greater than $V_{A C}$ and according to (10), $I_{S}$ will be capacitive, while small positive values of $\beta$ make $V_{l}$ smaller than $V_{A C}$ and subsequently, $I_{S}$ will be inductive. The response of a certain STATCOM to $\beta$ changing depends on many factors such as inverter switching losses, switching devices ON and OFF times, the dead time $T_{D}$ between the triggering pulses of the switching devices on the same limb, modulation index, and passive element values. Some controlling techniques adopted phase-shifted sinusoidal PWM (SPWM) to control the current of the Hbridge STATCOM [14]. The study proposed by [15] had adopted the phase-shifted multicarrier unipolar PWM to control the STATCOM current. This type of control helps to decrease the effect of multi-switching during STATCOM triggering. Many techniques subjected STATCOM current control to lookup tables relating $\beta$ values to the magnitude and phase values of the STATCOM current [8], [16]-[18]. Closed loop techniques are widely used to control STATCOM current by comparing the STATCOM current with a reference one. In these techniques, phase locked loops are usually employed to synchronize the STATCOM with the grid [10], [19]-[20]. Proportional and proportional integral controllers are broadly employed for STATCOM current control [13], [21]-[25].

The STATCOM shown in Figure 1 is modified here to meet the requirements of being continuously and linearly controlled harmonic-free compensating susceptance. The modification is involved in two steps; in the first step $V_{D C}$ is kept constant at a certain level for each compensating current without using external energy injection or storage devices, while in the second step, the reactive compensating current is brought to its steady state value within a shorter time compared with other controlling techniques [16], [17]-[25].

The first step of STATCOM modification is accomplished by using a series harmonic filter connected in parallel with $V_{D C}$ as shown in Figure 3. The second step represents the most important modification and is accomplished by devising a new controlling technique. In this technique, the STATCOM angle $\beta$ is controlled within a range of $-5.73^{\circ}$ to $+5.73^{\circ}$. In this range of $\beta$, the modified STATCOM current is guaranteed to be pure reactive (either capacitive or inductive). 


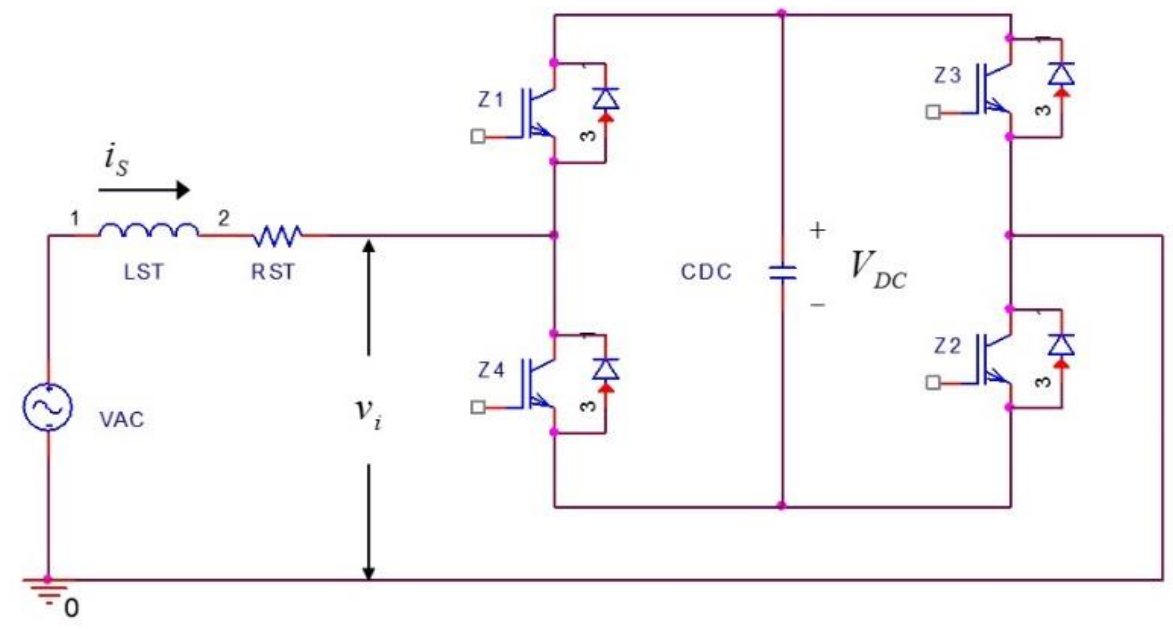

Figure 1. The VSI-based H-bridge STATCOM

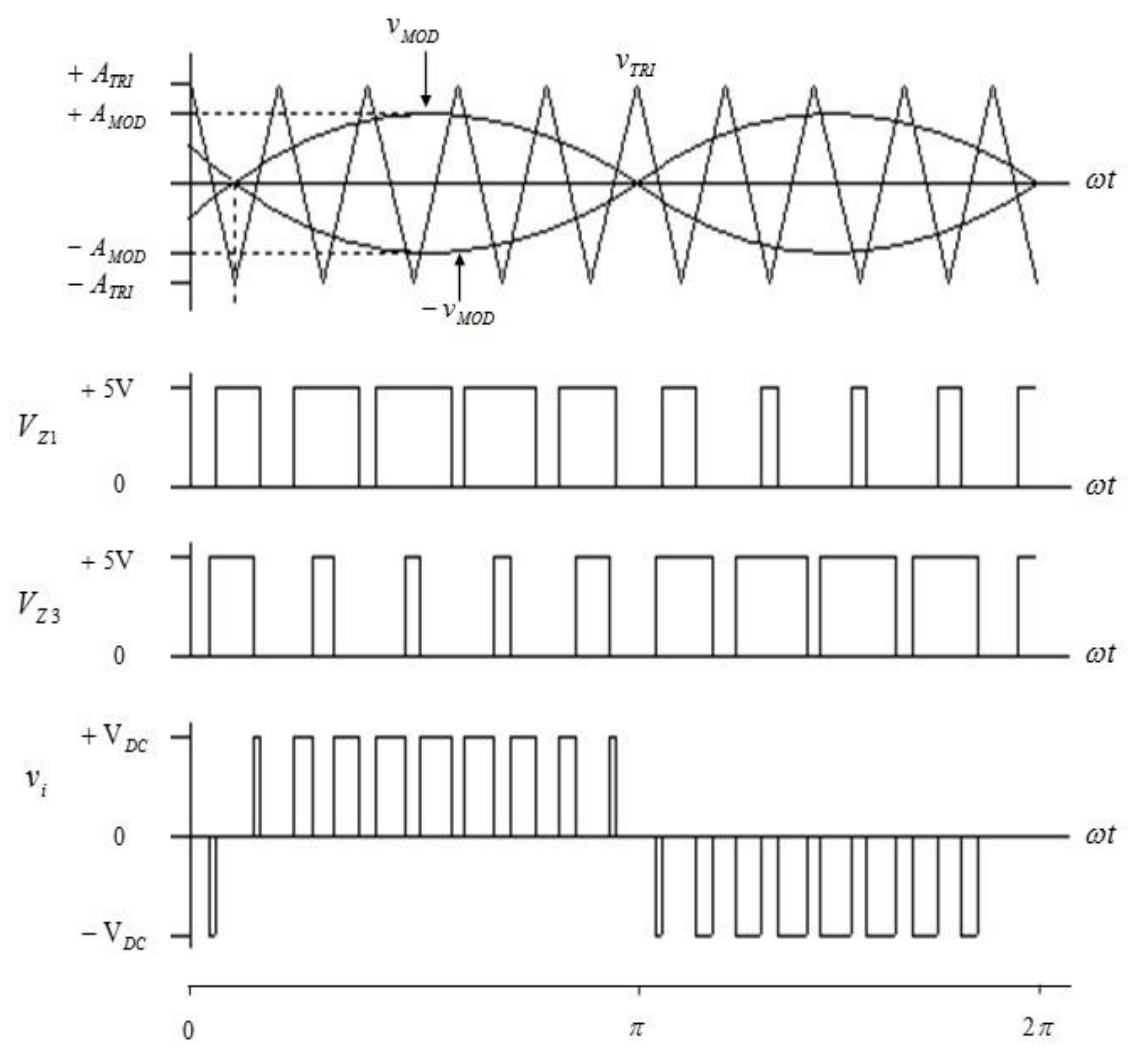

Figure 2. USPWM triggering signals generation of the VSI-based STATCOM 


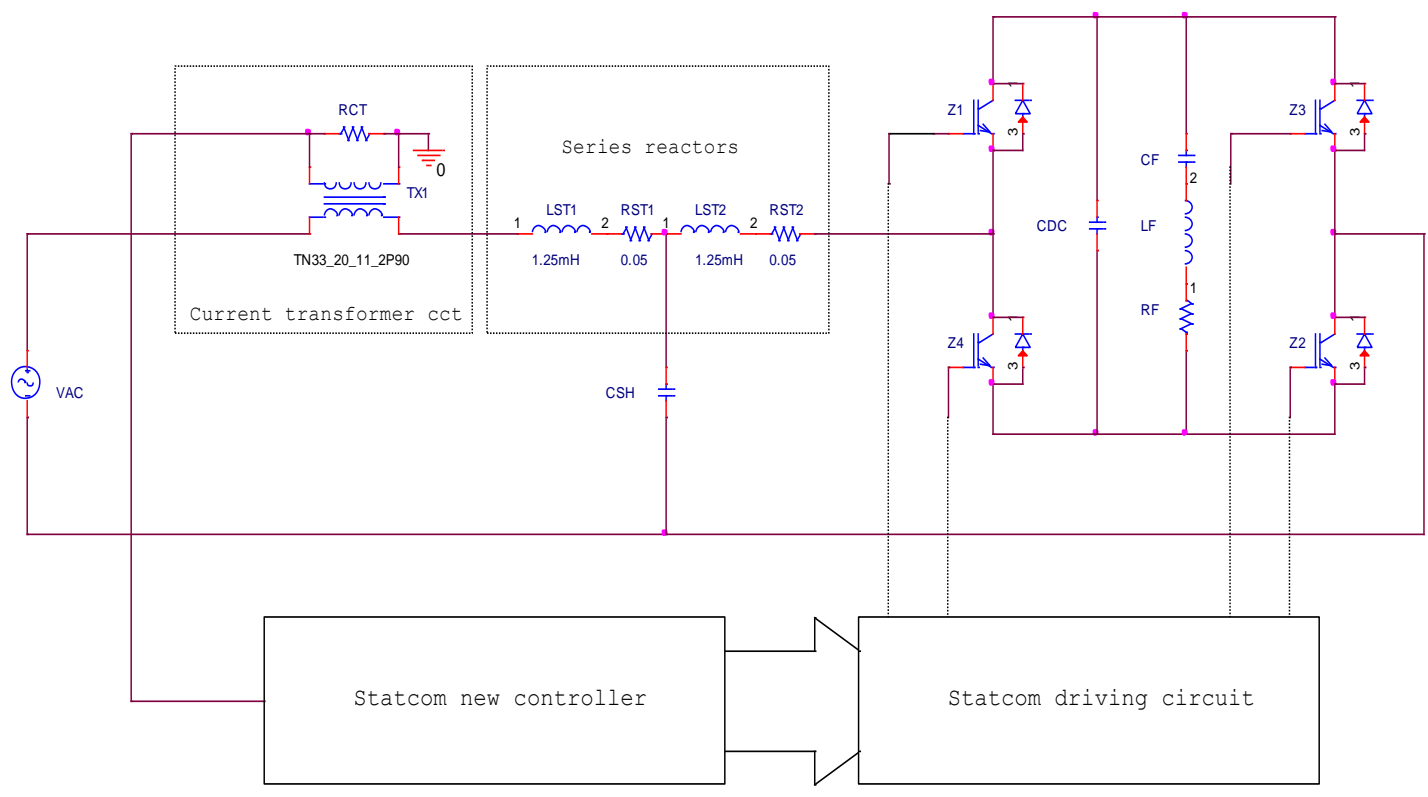

Figure 3. The layout of the proposed linearized STATCOM

\section{a. The devised controlling technique}

The schematic modeling of the devised controlling technique is shown in Figure 4. After detecting the STATCOM instantaneous current $i_{S}$ by the current transformer and converting it to the voltage signal $k_{S} i_{s}$, the latter signal is processed within the sample and hold circuits to get the analogue voltage $k_{S} I_{S m}$. Where, $I_{S m}$ is the amplitude of $i_{S}$ and $k_{S}$ is a constant depending on the current transformer primary to secondary turn ratio and the resistor $R_{C T}$. The analogue voltage $k_{S} I_{S m}$ is subtracted from $k_{S} I_{D m}$ which is another analogue signal proportional to the amplitude of the required reactive demand $I_{D m}$. The result of subtraction is $\Delta k_{S} I_{S m}$ which is an analogue voltage proportional to the amount of deviation of the actual STATCOM current from the required reactive current demand. Note that $I_{S m}$ is a polar quantity. Its value is positive during capacitive reactive current demand and negative during inductive current demand. This means that detecting $I_{S m}$ means detecting the magnitude and phase of the STATCOM current. The most important part of the above controller is the STATCOM angle controller. It involves two identical NPN bipolar junction transistors $Q_{1}$ and $Q_{2}$ which are biased in the active regions near cutoff. $V \gamma$ is the cut in threshold voltage of these transistors. According to the biasing status of $Q_{1}$ and $Q_{2}$, their base currents $i_{B 1}$ and $i_{B 2}$ can be expressed as (11) and (12)

$$
\begin{aligned}
& i_{B 1}=\frac{\Delta V(\beta)}{R_{B 1}}, \Delta V(\beta) \geq 0 \\
& i_{B 2}=\frac{-\Delta V(\beta)}{R_{B 2}}, \Delta V(\beta) \leq 0
\end{aligned}
$$

Where, $\Delta V(\beta)$ is an analogue voltage signal proportional to the error of the STATCOM angle $\beta$. If $Q_{1}$ and $Q_{2}$ are in their active regions, then their collector currents $i_{C l}$ and $i_{C 2}$ can be determined as (13) and (14):

$$
\begin{aligned}
& i_{C 1}=h_{F E} i_{B 1}=\frac{h_{F E} \Delta V(\beta)}{R_{B 1}}, \Delta V(\beta) \geq 0 \\
& i_{C 2}=h_{F E} i_{B 2}=\frac{-h_{F E E} \Delta V(\beta)}{R_{B 2}}, \Delta V(\beta) \leq 0
\end{aligned}
$$

Where, $h_{F E}$ is the forward DC current gain of the common emitter configuration. The DC forward current gain is used in this analysis, since the transistor's input voltages are slow varying signals. In case of saturation, the currents $i_{C l}$ and $i_{C 2}$ can be given by (15) and (16) 


$$
\begin{aligned}
& i_{C 1}=\frac{V_{C C}-V(\beta)}{R_{C 1}}, \Delta V(\beta) \geq 0 \\
& i_{C 2}=\frac{V(\beta)+V_{C C}}{R_{C 2}}, \Delta V(\beta) \leq 0
\end{aligned}
$$

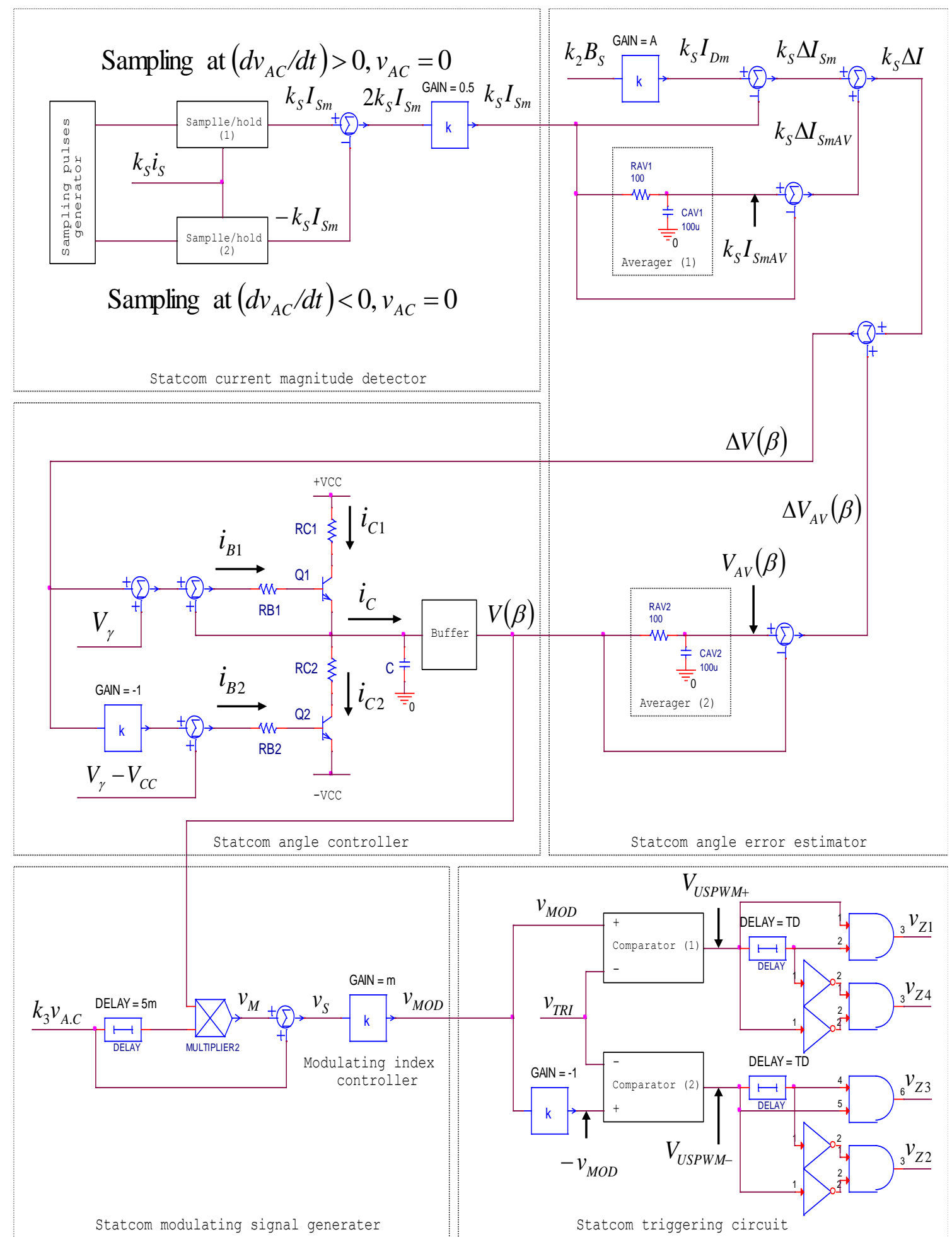

Figure 4. The devised controlling scheme 
Where, $V(\beta)$ is an analogue voltage signal proportional to the STATCOM angle. If $V(\beta)$ is more positive than $V_{C C}$ or more negative than $-V_{C C}$, then (15) and (16) are no longer being applicable. The current $i_{C}$ of the capacitor $C$ is determined as (17):

$$
i_{C}=\left(\begin{array}{l}
i_{C 1}+i_{B 1}, \Delta V(\beta) \geq 0 \\
-i_{C 2}, \Delta V(\beta) \leq 0
\end{array}\right)
$$

The voltage across the capacitor $C$, is $V(\beta)$ which represents the analogue signal controlling a part in this controller responsible for generating the modulating signal $v_{M O D}$. The analogue signal $V(\beta)$ can be expressed as (18):

$$
V(\beta)=\frac{1}{C} \int i_{C} d t
$$

The error signal $\Delta V(\beta)$ is determined by (19)

$$
\Delta V(\beta)=\Delta V_{A V}(\beta)+k_{S} \Delta I
$$

where, $\Delta V_{A V}(\beta)$ and $\Delta I$ are defined by (20) and (21)

$$
\begin{aligned}
& \Delta V_{A V}(\beta)=V_{A V}(\beta)-V(\beta) \\
& \Delta I=\Delta I_{S m}+\Delta I_{S m A V}
\end{aligned}
$$

where, $V_{A V}(\beta)$ represents the instantaneous average value of $V(\beta)$, and the current error components $\Delta I_{S m}$ and $\Delta I_{S m A V}$ are defined by (22) and (23)

$$
\begin{aligned}
& \Delta I_{S m}=I_{D m}-I_{S m} \\
& \Delta I_{S m A V}=I_{S m A V}-I_{S m}
\end{aligned}
$$

Where, $I_{S m A V}$ is the instantaneous average value of $I_{S m}$. As $i_{C}$ grows positive rapidly, $V(\beta)$ builds up rapidly too and it may make significant overshoots. The error signals defined by the terms $k_{S} \Delta I_{S m A V}$ and $\Delta V_{A V}(\beta)$ decrease the chances for $V(\beta)$ to exhibit overshoots and make the STATCOM current tend faster toward its desired value. Both terms vanish as $V(\beta)$ attains its steady state value. The analogue voltage $V(\beta)$ determines the phase angle by which, the modulating signal $v_{M O D}$ will be shifted from the original AC voltage applied across the STATCOM terminals. $V(\beta)$ varies in the range of $-V_{C C}$ to $+V_{C C}$. If $\Delta V(\beta)$ is positive, $C$ will charge through $Q_{1}$ towards $V_{C C}$, while $C$ will discharge towards - $V_{C C}$ through $Q_{2}$ if $\Delta V(\beta)$ becomes negative. The STATCOM modulating signal generator is built of a time delayer of $5 \mathrm{msec}$, analogue multiplier, summer, and a voltage amplifier of forward gain of $m$ which is related directly to the STATCOM modulation index. The analogue voltage $k_{3} v_{A C}$ is a low voltage sinusoidal signal proportional to the AC supply voltage. For a $50-\mathrm{Hz}$ AC power supply, the $5 \mathrm{msec}$ delay represents a phase delay of $\pi / 2$. If the AC voltage $v_{A C}$ is expressed as $V_{m} \sin (\omega t)$, then the output of the analogue multiplier $v_{M}$ will be determined as (24):

$$
v_{M}=k_{3} V_{m} \sin \left(\omega t-\frac{\pi}{2}\right) V(\beta) A_{M}=-V(\beta) A_{M} k_{3} V_{m} \cos (\omega t)
$$

where, $V_{m}$ is the amplitude of $v_{A C}$ and $A_{M}$ is the gain of the analogue multiplier. The summing amplifier output $v_{S}$ can be given by (25)

$$
\begin{aligned}
v_{S} & =k_{3} v_{A . C}+v_{M}=k_{3} V_{m} \sin (\omega t)-V(\beta) A_{M} k_{3} V_{m} \cos (\omega t) \\
& =k_{3} V_{m}\left(\sqrt{\left(A_{M} V(\beta)\right)^{2}+1}\right) \sin \left(\omega t-\tan ^{-1}\left(A_{M} V(\beta)\right)\right)
\end{aligned}
$$

If $\left.\mid A_{M} V(\beta)\right) \mid$ is very much less than unity, (25) can be reduced to (26)

$$
v_{S} \cong k_{3} V_{m} \sin \left(\omega t-A_{M} V(\beta)\right)=k_{3} V_{m} \sin (\omega t+\beta)
$$

where, $\beta$ is defined by (27) 


$$
\beta=-A_{M} V(\beta)
$$

By varying $\beta$ in the range of $(-0.1$ to +0.1$)$ radians, the voltage generated by the STATCOM varies from minimum to maximum. This radian range corresponds to a degree range of $-5.73^{0}$ to $+5.73^{0}$. The maximum capacitive current of the STATCOM corresponds to $\beta$ of $-5.73^{0}$, while the maximum inductive current corresponds to $\beta$ of $+5.73^{0}$. By varying $\beta$ from $+5.73^{0}$ to $-5.73^{0}$, the STATCOM current can be varied from maximum inductive to maximum capacitive.

\section{b. Design of the proposed linearized STATCOM}

Figure 5 shows the PSpice implementation of the modified statcom. In this figure, the STATCOM controller involves the generated electronic parts simulating the schematic design items shown Figure 4.
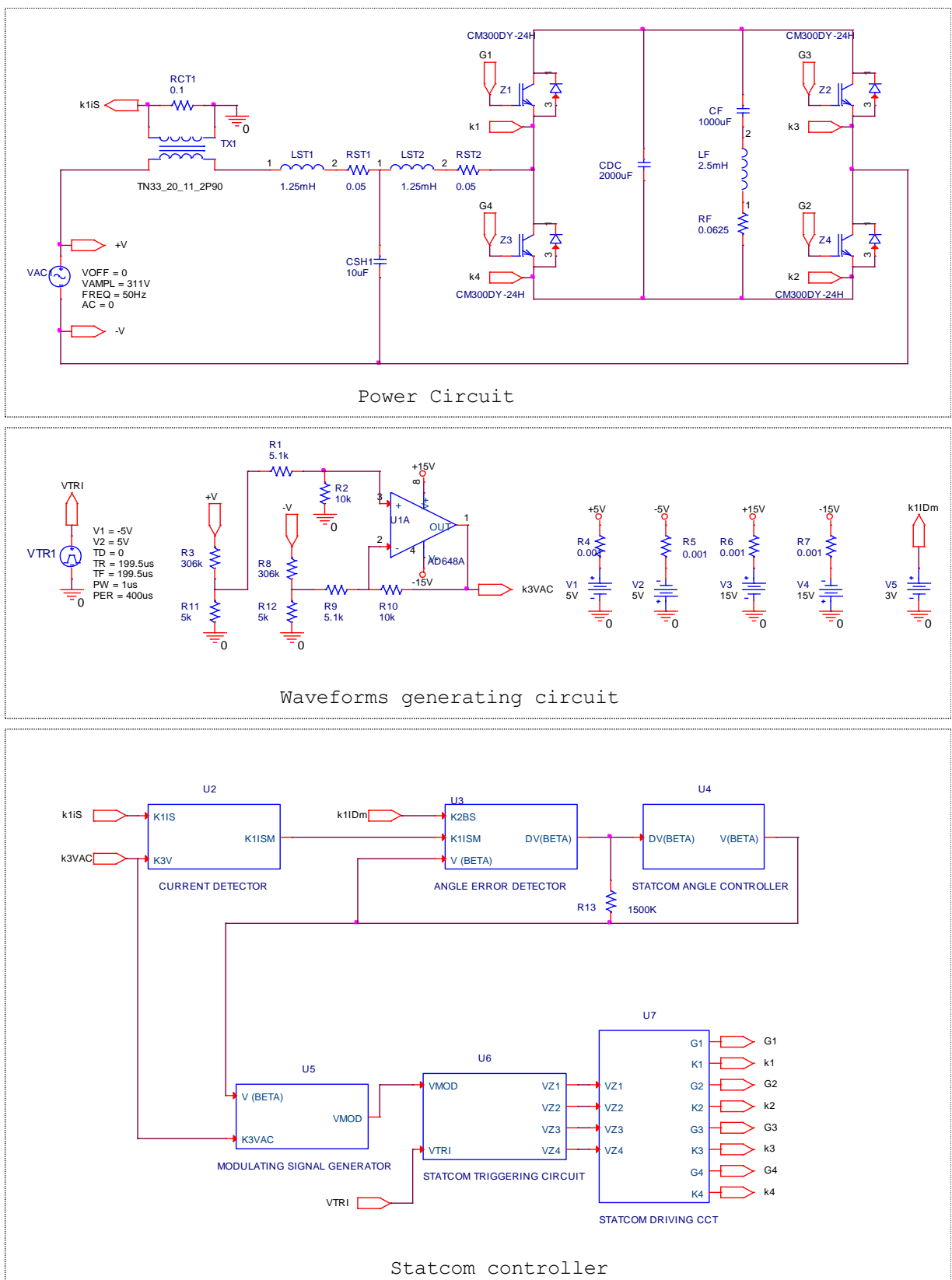

Figure 5. The PSpice implementation of the modified STATCOM 
The current transformer used in the designed STATCOM, has a primary to secondary turn ratio of 0.2 , therefore the constant $k_{S}$ is calculated to be $0.02 \Omega$ taking into account the $0.1 \Omega$ value of $R_{C T}$ (the resistor shunting the current transformer). The voltage source $V_{5}$ represents the analogue signal $k_{l} I_{D m}$. Negative and positive values of $V_{5}$ are corresponding to capacitive and inductive reactive current demands, respectively. The AC voltage used is of amplitude of $311 \mathrm{~V}(220 \mathrm{~V}$ rms value) and frequency of $50 \mathrm{~Hz}$. The IGBT used is of the type of CM300DY-24H which has maximum continuous voltage and current ratings of $1200 \mathrm{~V}$ and $300 \mathrm{~A}$, respectively. The carrier frequency is $2.5 \mathrm{KHz}$ and $m$ is about 0.98 . The modified STATCOM is designed to satisfy a peak reactive current demand of 250A (capacitive or inductive). The driving circuit of the STATCOM is shown in Figure 6. It is composed of four identical sub-driving circuits; each one of them is responsible for driving one IGBT of the STATCOM.
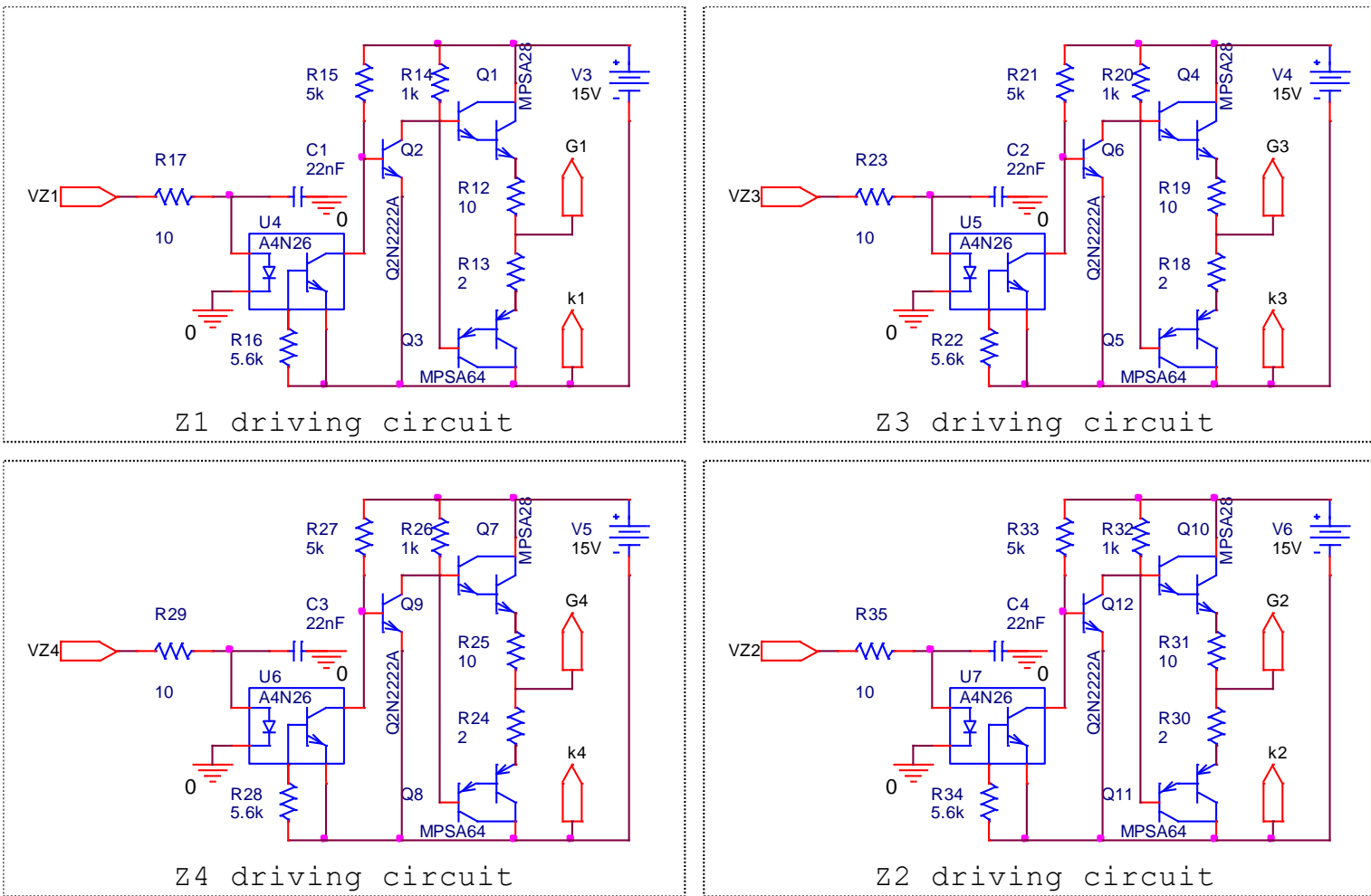

Figure 6. The PSpice implementation of the STATCOM driving circuit

\section{RESULTS AND DISCUSSION}

In this section, there are two groups of results; the first reflects the the performance of the adopted current controller, while the second reveals the performance of the propsed STATCOM at different reactive current demands.

\subsection{Performance of the adopted current controller}

The performance of the PSpice implemented STATCOM is reflected in the test results shown in Figure 7 to Figure 9. These figures show that the linearized STATCOM current $i_{S}$ approaches its steady state value within a time less than $100 \mathrm{msec}$ which is the time less than any time elapsed in other controlling techniques [16], [17]-[25]. A $+3 \mathrm{~V}$ value of $k_{1} I_{D m}$ corresponds to a capacitive reactive current demand of $150 \mathrm{~A}$ (peak value), while $-3 \mathrm{~V}$ corresponds to inductive reactive current demand of 150A (peak value). Figure 7 shows that the STATCOM current is pure capacitive, while Figure 8 shows that its current is pure inductive. Figure 9 shows that the STATCOM current tends to zero during zero reactive current demand. The nature of the STATCOM current (capacitive or inductive) is revealed within the first cycle of $v_{A C}$, although the DC capacitor requires long charging time. Overall, the proposed STATCOM responds precisely to reactive current demand within its range of operation without harmonics association, thus it can be promoted as an adaptive bipolar (capacitive and inductive) static Var compensator (SVC) showing continuously and linearly controlled harmonic-free compensating susceptance. 

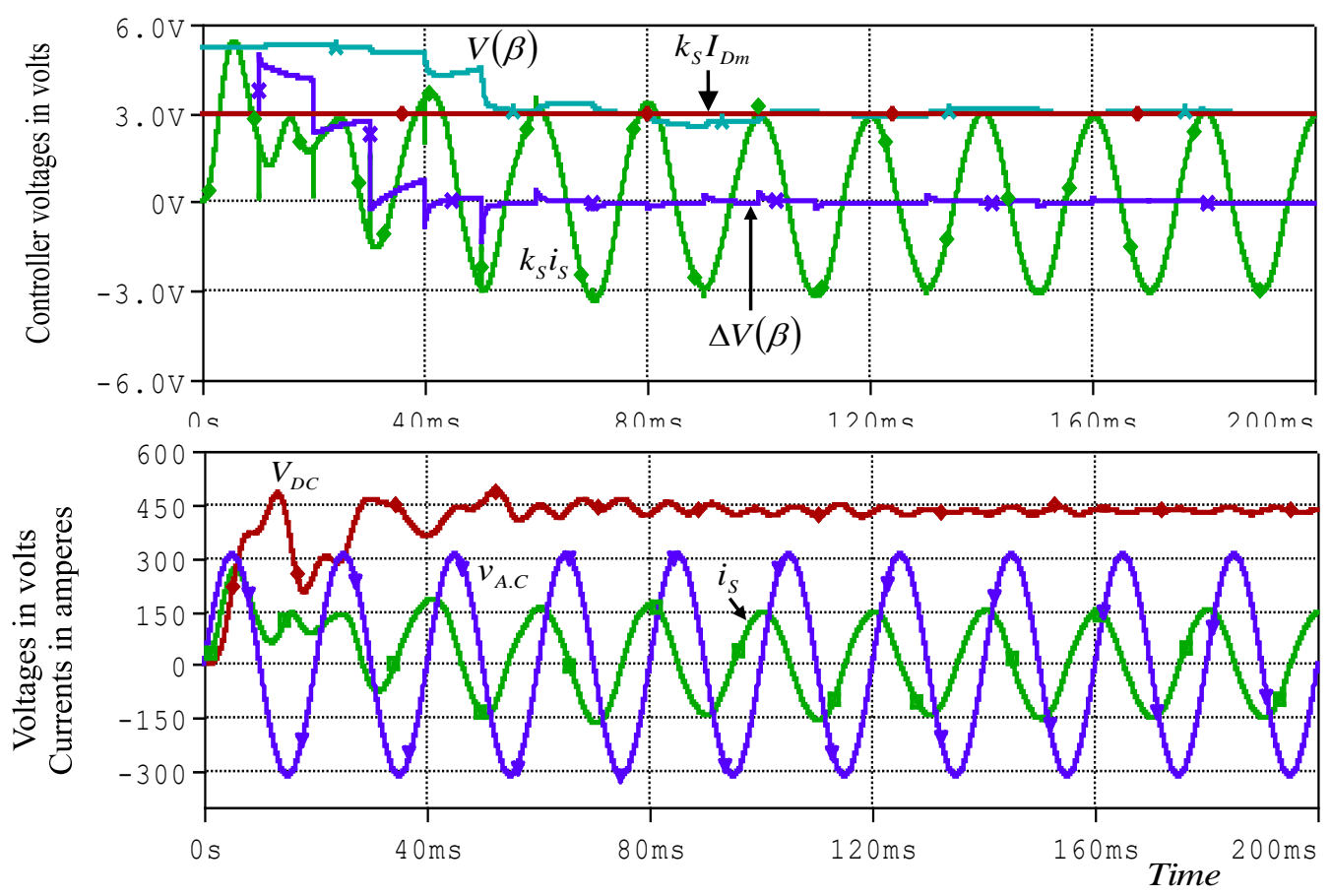

Figure 7. Controller and STATCOM responses to capacitive current demand of 150A (peak value)
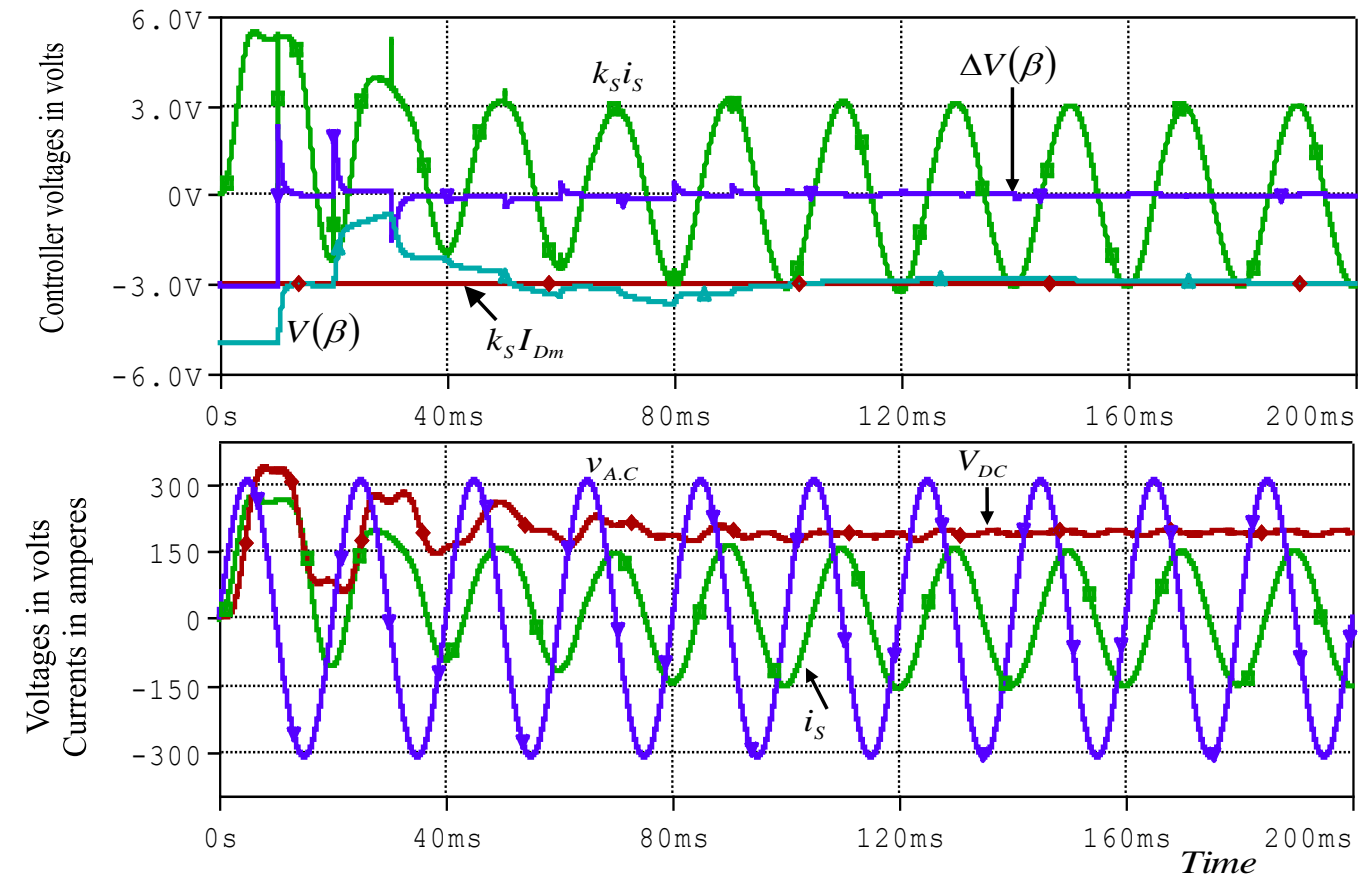

Figure 8. Controller and STATCOM responses to inductive current demand of 150A (peak value). 

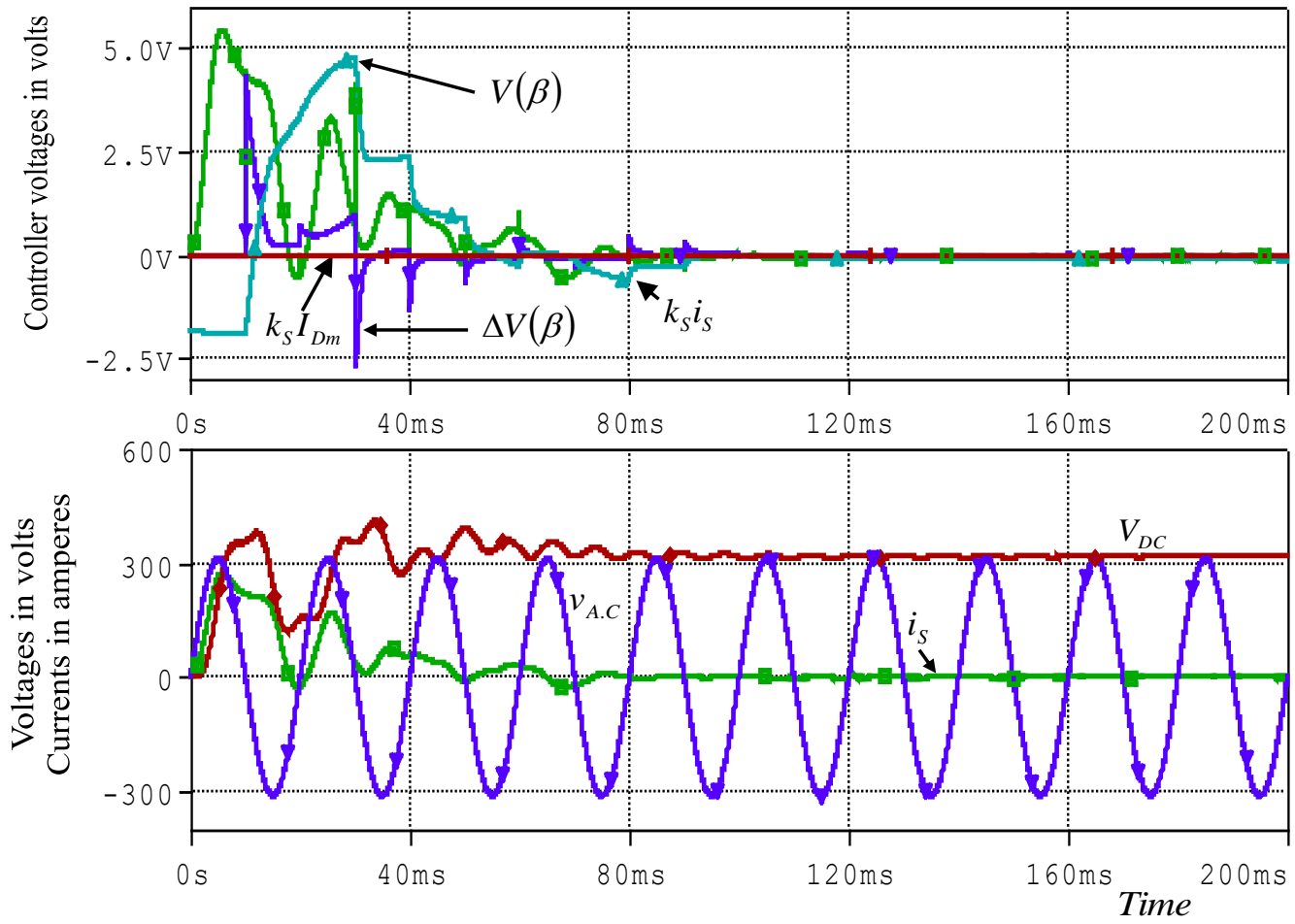

Figure 9. Controller and STATCOM responses to zero reactive current demand

\subsection{Performance results of $220-\mathrm{V}, \mathbf{5 0}-\mathrm{Hz}$ linearized STATCOM}

The circuit diagram of $220-\mathrm{V}, 50-\mathrm{Hz}$ linearized STATCOM is shown in Figure 10. The harmonic contents, control continuity and linearity of this STATCOM were investigated on PSpice. The AC voltage used during PSpice tests was a zero phase sinusoidal voltage having frequency of $50 \mathrm{~Hz}$ and amplitude of $311 \mathrm{~V}$ (corresponding to an rms value of $220 \mathrm{~V}$ ). The parameters measured through PSpice tests were the STATCOM current $i_{S}$, the DC capacitor voltage $V_{D C}$, and the AC phase voltage $v_{P}$. The basic controlling signal of this statcom is $k_{l} I_{D m}$. The transient and steady state responses of this statcom during zero reactive current demand (corresponded to $k_{I} I_{D m}=0$ ) are shown in Figure 10.

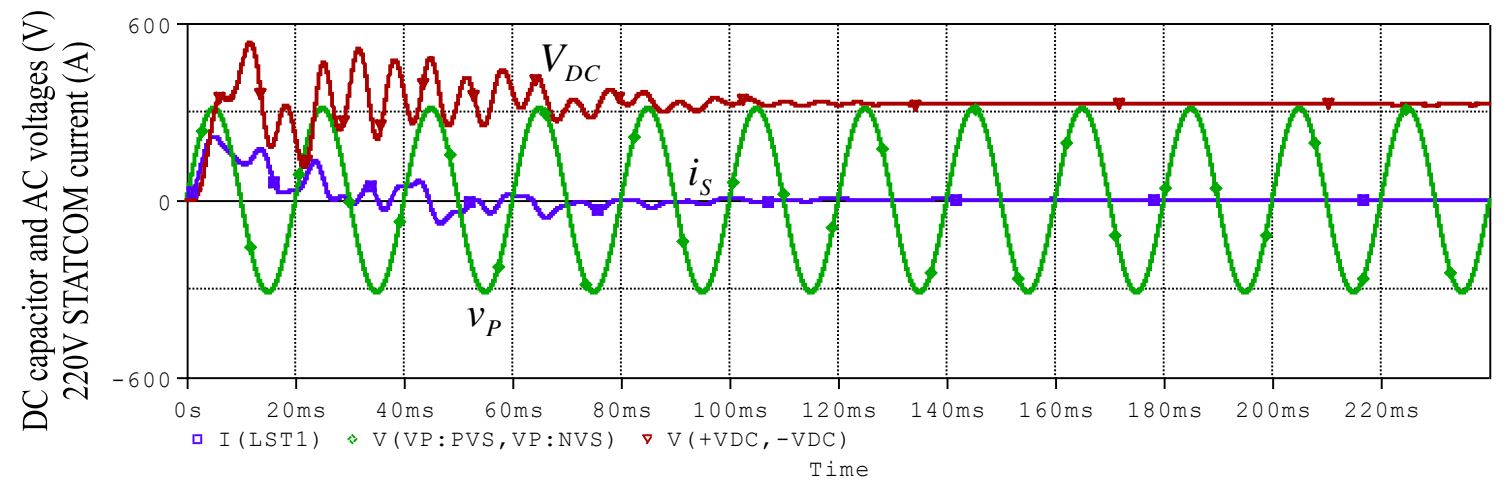

Figure 10. Transient and steady state responses of the proposed STATCOM to zero reactive current demand

Figure 11 shows the transient and steady state responses of the $220-\mathrm{V}, 50-\mathrm{Hz}$ linearized STATCOM to an inductive reactive current demand of $61.5 \mathrm{~A}$ (peak value). This amount of reactive current demand corresponded to $k_{l} I_{D m}$ of a value of $-1.23 \mathrm{~V}$. As specified above, the maximum capacitive reactive of this STATCOM is $227 \mathrm{~A}$ (peak value) and maximum inductive current rating is $123 \mathrm{~A}$ (peak value). Figure 12 shows the transient and steady states operation of the $220-\mathrm{V}, 50-\mathrm{Hz}$ linearized STATCOM during its 
response to a maximum inductive current demand of $123 \mathrm{~A}$ (peak value). This current corresponded to $k_{l} I_{D m}$ of $-2.46 \mathrm{~V}$.

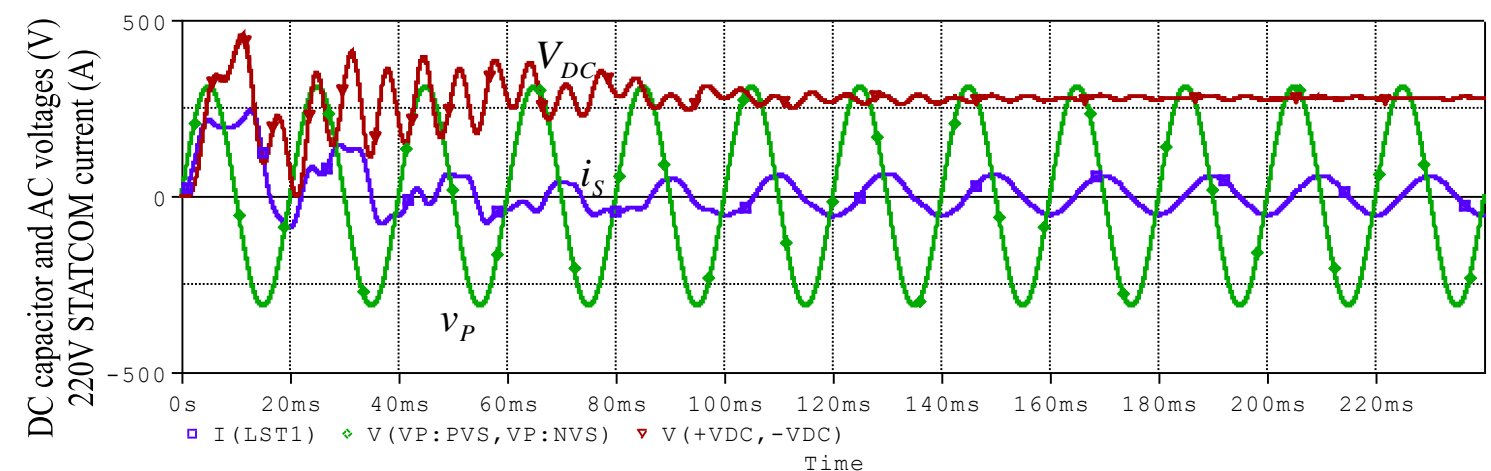

Figure 11. Transient and steady state responses of the proposed STATCOM to an inductive current demand of $61.5 \mathrm{~A}$ (peak value)

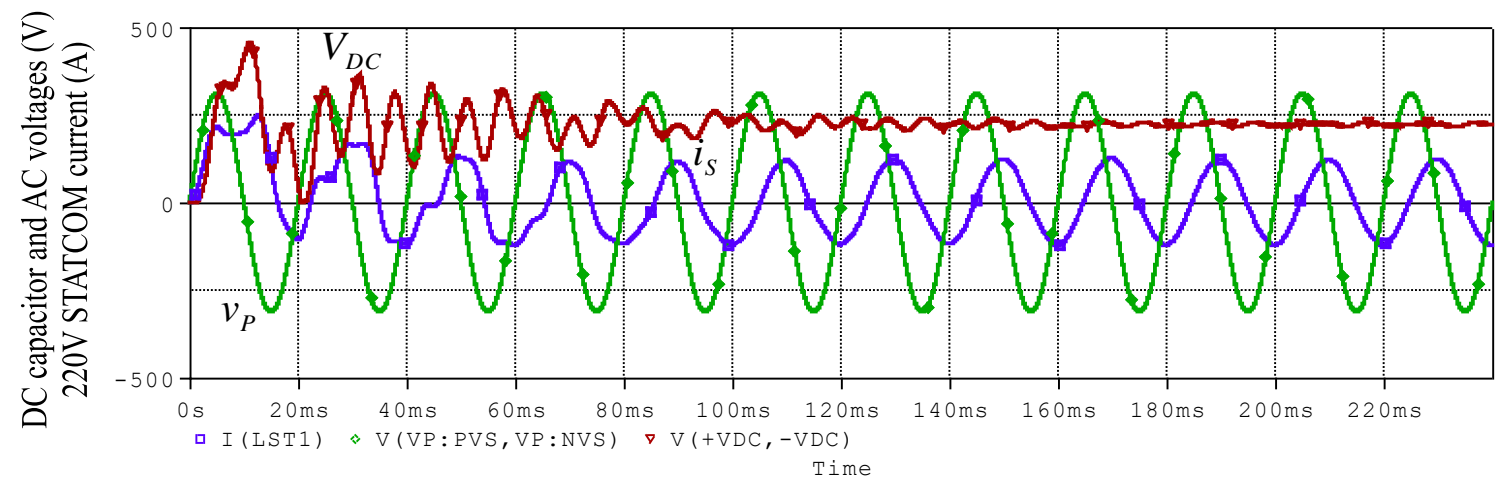

Figure 12. Transient and steady state responses of the proposed STATCOM to an inductive current demand of $123 \mathrm{~A}$ (peak value)

The transient and steady states operation results of this Transient and steady state responses of the proposed STATCOM to during capacitive mode of operation are shown in Figure 13 to Figure 16. These figures reflect the Transient and steady state responses of the proposed STATCOM performance during different capacitive reactive current demands starting from $25 \%$ up to $100 \%$ of the STATCOM capacitive reactive current rating. The maximum capacitive susceptance of this statcom corresponds to a capacitive reactive current demand of $227 \mathrm{~A}$, thus the value of this susceptance is calculated to be $227 \mathrm{~A} / 311 \mathrm{~V}=0.723 \sigma$. This value of susceptance corresponds to $k_{1} I_{D m}$ of $4.54 \mathrm{~V}$. Figure 13 states that the DC capacitor voltage settled to its steady value within $100 \mathrm{msec}$ since the first plug in instant of the $220-\mathrm{V}, 50-\mathrm{Hz}$ STATCOM to the AC source. The nature of the capacitive current appears after $20 \mathrm{~ms}$ since the first plug in instant of the 220-V, 50-Hz STATCOM to the AC source. 


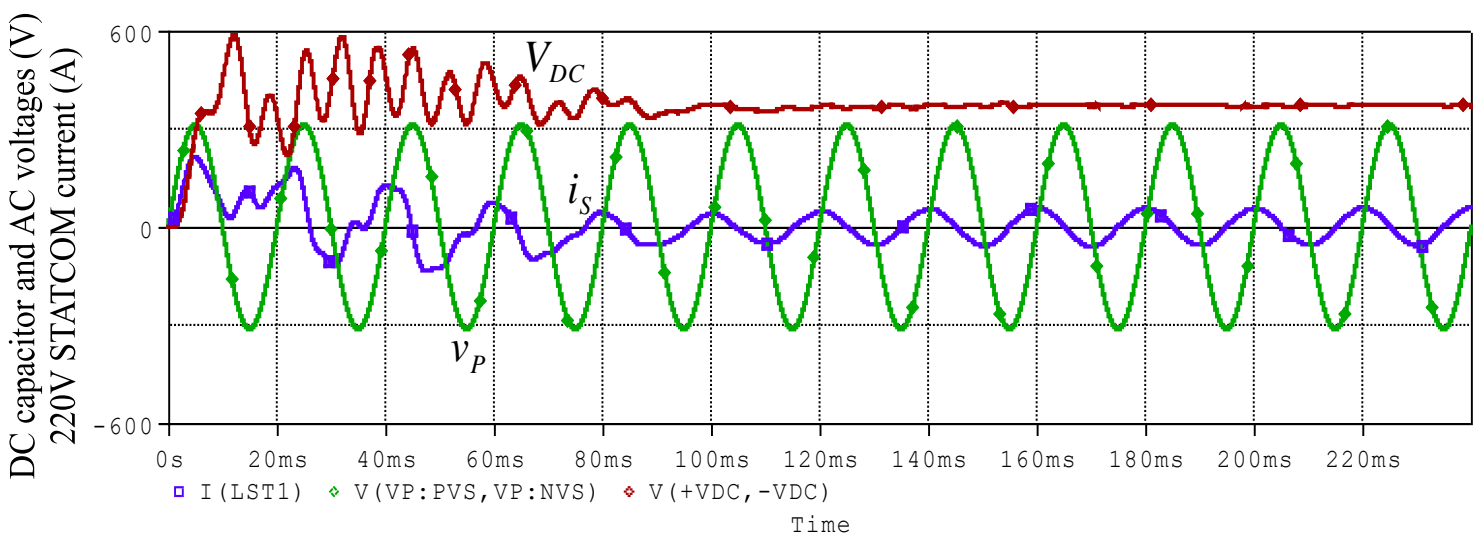

Figure 13. Transient and steady state responses of the proposed STATCOM to a capacitive reactive current demand of 56.75A (peak value)

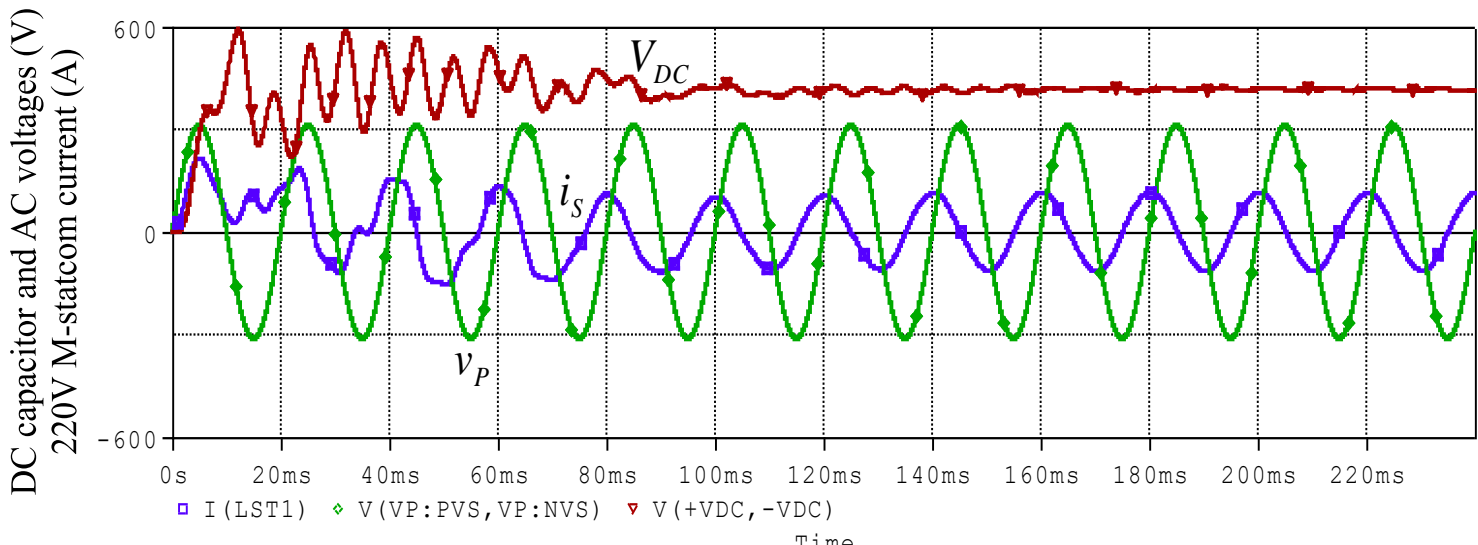

Figure 14. Transient and steady state responses of the proposed STATCOM to a capacitive reactive current demand of 113.5A (peak value)

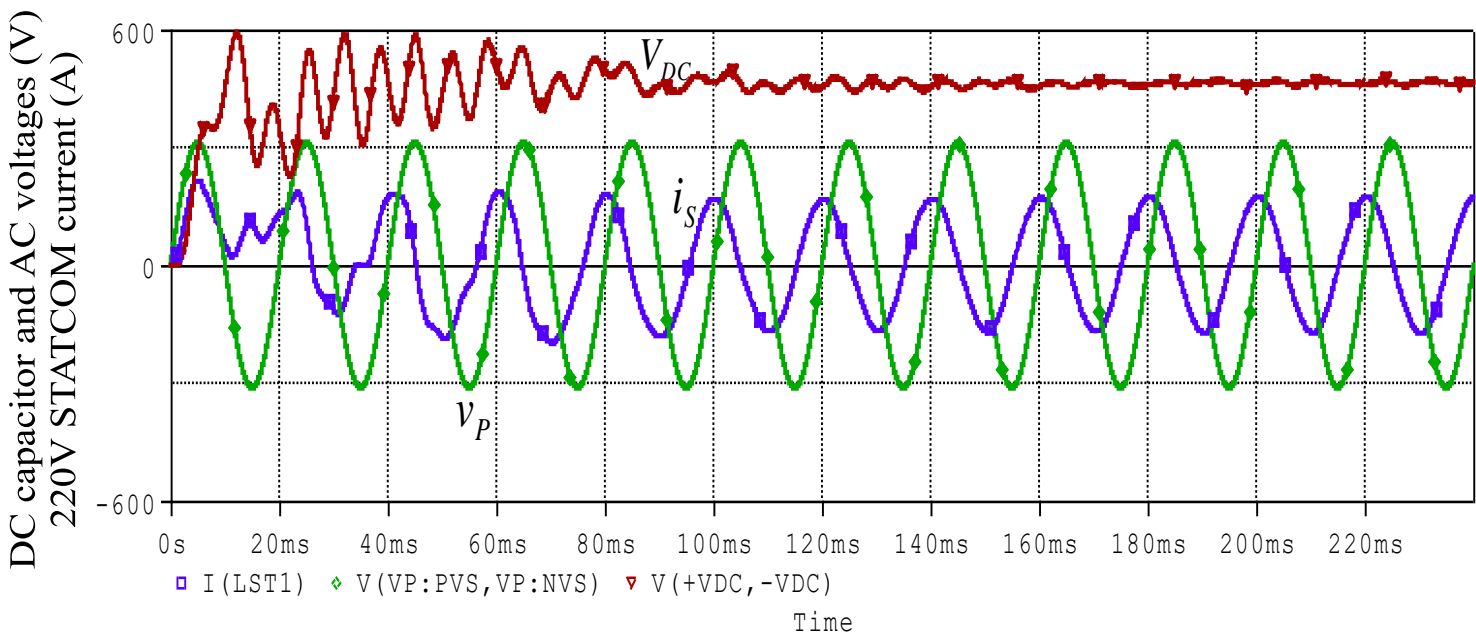

Figure 15. Transient and steady state responses of the proposed STATCOM to a capacitive reactive current demand of $170.25 \mathrm{~A}$ (peak value) 


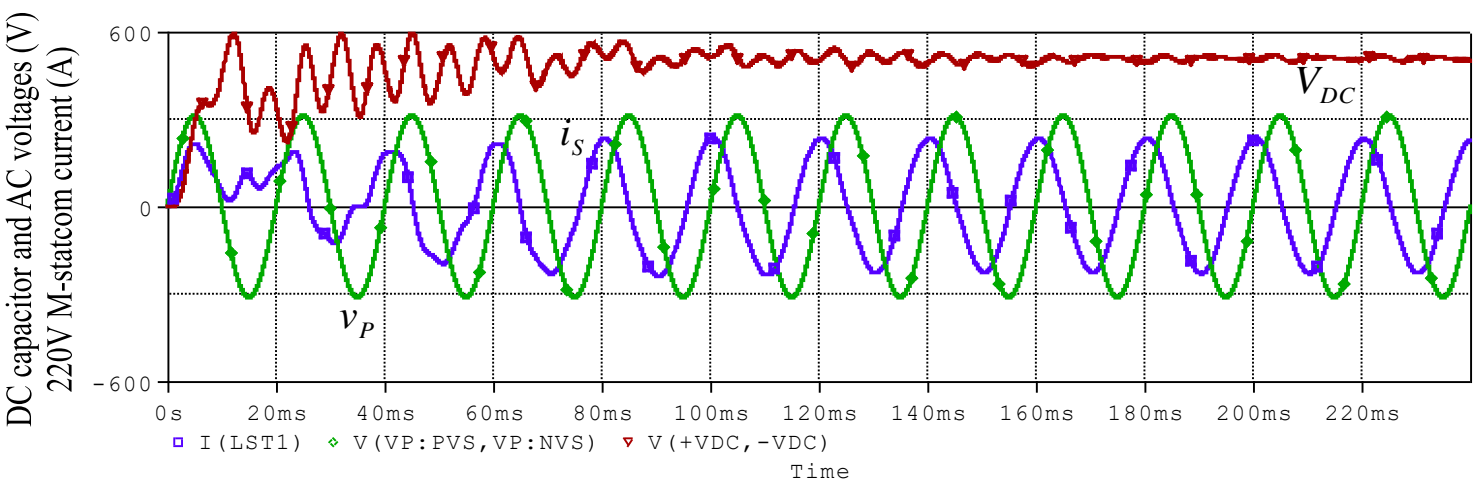

Figure 16. Transient and steady state responses of the proposed STATCOM to a capacitive reactive current demand of 227A (peak value)

In inductive and capacitive modes of operation, the STATCOM current exhibits peaks at the zero crossing points of the AC source voltage. Consequently, it can be said that the proposed $220-\mathrm{V}, 50-\mathrm{Hz}$ STATCOM is a pure reactive device. The response of this STATCOM to sudden change in reactive current demand from maximum inductive to maximum capacitive is shown in Figure 17. The change in reactive demands occurred at $\mathrm{t}=200 \mathrm{~ms}$ and the transition period elapsed $40 \mathrm{~ms}$. The linearity of this STATCOM is demonstrated by the graph shown in Figure 18. The graph is accomplished through exploiting the steady state responses shown in Figure 10 to Figure 16. It is obvious that there are negligible current components in the STATCOM current in steady state regions of the current responses. Overall, the proposed 220-V, $50-\mathrm{Hz}$ STATCOM is verified as continuously and linearly controlled harmonic-free compensating susceptance. The proposd current controller has short response time compared to controlling schemes mentioned in [16], [17]-[25].
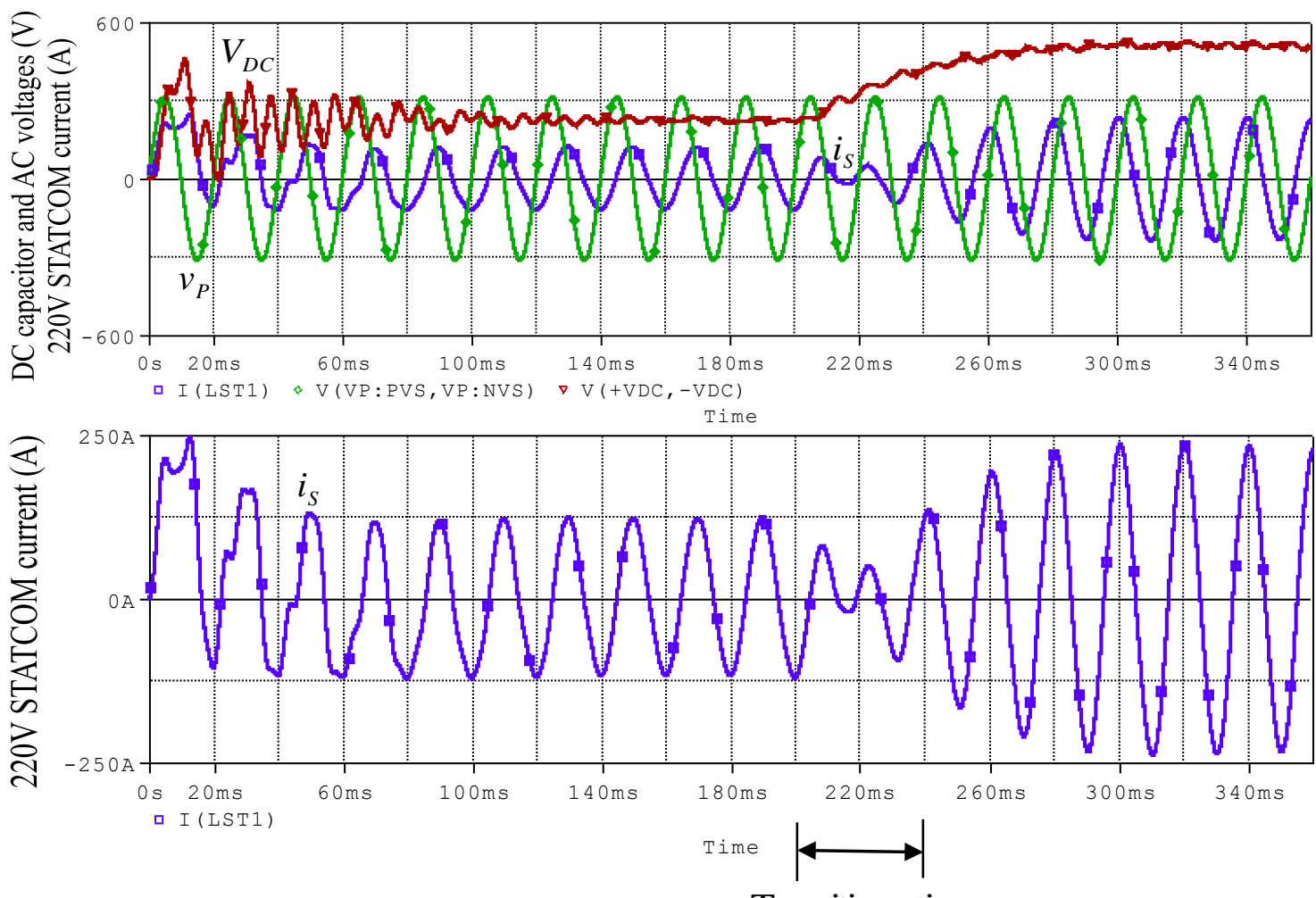

Transition time

Figure 17. STATCOM performance during sudden change in reactive current demand from maximum inductive to maximum capacitive 


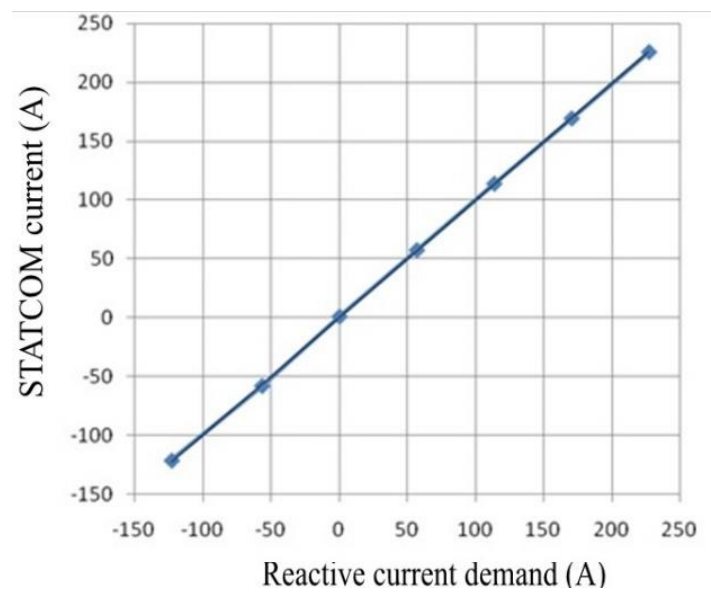

Figure 18. The proposed STATCOM current against reactive current demand

\section{CONCLUSION}

The proposed STATCOM has been demonstrated as a continuously and linearly controlled susceptance in capacitive and inductive mode of operations, thus it can considerably be exploited in load current balancing systems to achieve better power quality and energy saving. The promotion is achieved through the modification of the traditional H-bridge VSI based STATCOM via devising new current controller and keeping the STATCOM DC capacitor voltage constant at a certain level for each compensating current without using external energy injection or storage devices. The response of this STATCOM to sudden change in reactive current demand from maximum inductive to maximum capacitive requires a transition period of $40 \mathrm{~ms}$.

\section{REFERENCES}

[1] Y. Sumi, Y. Hanunoto, T. Hasegawa, M. Yano, K. Ikeda, and T. Matsuura, "New Static VAR Control using Forced-Commutated Inverter," IEEE Transactions on Power Apparatus and Systems, vol. PAS-100, pp. 4216-4224, Sep. 1981.

[2] P. García-González and A. García-Ce, "Control System for a PWM-Based STATCOM," IEEE Transactions on Power Delivery, vol. 15, pp. 1252-1257, Oct. 2000.

[3] Y. H. Liu, J. Arrillaga, and N. R. Watson, "A New STATCOM Configuration Using Multi-Level DC Voltage Reinjection for High Power Application,” IEEE Transactions on Power Delivery, vol. 19, pp. 1828-1834, Oct. 2004

[4] Y. Ye, M. Kazerani, and V. H Quintana, "Current-Source Converter Based STATCOM: Modeling and Control," IEEE Transactions on Power Delivery, vol. 20, pp. 795-800, Apr. 2005.

[5] K. Li, J. Liu, Z. Wang, and B. Wei, "Strategies and Operating Point Optimization of STATCOM Control for Voltage Unbalance Mitigation in Three-Phase Three-Wire Systems," IEEE Transactions on Power Delivery, vol. 22, pp. 413-421, Jan. 2007.

[6] B. S. Chen and Y. Y. Hsu, "An Analytical Approach to Harmonic Analysis and Controller Design of a STATCOM," IEEE Transactions on Power Delivery, vol. 22, pp. 423-432, Jan. 2007.

[7] Q. Song, W. Liu, and Z. Yuan, "Multilevel Optimal Modulation and Dynamic Control Strategies for STATCOMs Using Cascaded Multilevel Inverters," IEEE Transactions on Power Delivery, vol. 22, pp. 1937-1946, Jul. 2007.

[8] H. Akagi, S. Inoue, and T. Yoshii, "Control and Performance of a Transformerless Cascade PWM STATCOM with Star Configuration," IEEE Transactions on Industry Applications, vol. 43, pp. 1041-1049, 2007.

[9] S. Hirve, K. Chatterjee, B. G. Fernandes, M. Imayavaramban, and S. Drawi, "PLL-Less Active Power Filter Based on One-Cycle Control for Compensating Unbalanced Loads in Three-phase Four-Wire System," IEEE Transactions on Power Delivery, vol. 22, pp. 2457-2465, Oct. 2007.

[10] J. A. Barrena, L. Marroyo, M. Á. R. Vidal, and J. R. T. Apraiz, "Individual Voltage Balancing Strategy for PWM Cascaded H-Bridge Converter-Based STATCOM," IEEE Transactions on Industrial Electronics, vol. 55, pp. 21-29, Jan. 2008 .

[11] B. Singh, P. Jayaprakash, T. R. Somayajulu, and D. P. Kothari, "Reduced Rating VSC with a Zig-Zag Transformer for Current Compensation in a Three-Phase Four-Wire Distribution System," IEEE Transactions on Power Delivery, vol. 24, pp. 249-259, Jan. 2009.

[12] Y. Xu, L. M. Tolbert, J. D. Kuek, and D. T. Rizy, "Voltage and Current Unbalance Compensation Using a Static VAR Compensator," IET Power Electron, vol. 3, pp. 977-988, Oct. 2010. 
[13] M. Hagiwara, R. Maeda, and H. Akagi, "Negative-Sequence Reactive-Power Control by a PWM STATCOM Based on a Modular Multilevel Cascade Converter (MMCC-SDBC)," IEEE Transactions on Industry Applications, vol. 48, pp. 720-729, 2012.

[14] L. S. Czarnecki and P. M. Haley, "Unbalanced Power in Four-Wire Systems and Its Reactive Compensation," IEEE Transactions on Power Delivery, vol. 30, pp. 53-63, 2015.

[15] R. Gupta, A. Ghosh, and A. Joshi, "Switching Characterization of Cascaded Multilevel-Inverter-Controlled Systems," IEEE Transactions on Industrial Electronics, vol. 55, pp 1047-1058, Mar. 2008

[16] F. Z. Peng, J. W. McKeever, and D. J. Adams, "A Power Line Conditioner Using Cascade Multilevel Inverters for Distribution Systems," IEEE Transactions on Industry Applications, vol. 34, pp 1293-1298, 1998.

[17] S. Filizadeh and A. M. Gole, "Harmonic Performance Analysis of an OPWM-Controlled STATCOM in Network Applications," IEEE Transactions on Power Delivery, vol. 20, pp. 1001-1008, Apr. 2005.

[18] M. Badoni, A. Singh, and B. Singh, "Implementation of Immune Feedback Control Algorithm for Distribution Static Compensator," IEEE Transactions on Industry Applications, vol. 55, pp. 918-927, 2019.

[19] B. T. Ooi, M. Kazerani, R. Marceau Z. Wolanski, F. D. Galiana, D. McGillis, and G. Joos, "Mid-point Siting of FACTS Devices in Transmission Lines," IEEE Transactions on Power Delivery, vol. 12, pp. 1717-1722, Oct. 1997.

[20] R. Gupta, A. Ghosh, and A. Joshi, "Multiband Hysteresis Modulation and Switching Characterization for SlidingMode-Controlled Cascaded Multilevel Inverter," IEEE Transactions on Industrial Electronics, vol. 57, pp. 2344-2353, Jul. 2010

[21] A. Griffo and D. Lauria, "Two-Leg Three-Phase Inverter Control for STATCOM and SSSC Applications," IEEE Transactions on Power Delivery, vol. 23, pp. 361-370, Jan. 2008.

[22] J. J. Jung, J. H. Lee, S. K. Sul, G. T. Son, and Y. H. Chung, "DC Capacitor Voltage Balancing Control for DeltaConnected Cascaded H-Bridge STATCOM Considering Unbalanced Grid and Load Conditions," IEEE Transactions on Power Electronics, vol. 33, pp. 4726-4735, 2018.

[23] M. K. Mishra and K. Karthikeyan, "A Fast-Acting DC-Link Voltage Controller for Three-Phase DSTATCOM to Compensate AC and DC Loads," IEEE Transactions on Power Delivery, vol. 24, pp. 2291-2299, Oct. 2009.

[24] H. P. Mohammadi and M. T. Bina, "A Transformerless Medium-Voltage STATCOM Topology Based on Extended Modular Multilevel Converters," IEEE Transactions on Power Electronics, vol. 26, pp. 1534-1545, May 2011.

[25] B. Singh, P. Jayaprakash, S. Kumar, and D. P. Kothari, "Implementation of Neural-Network-Controlled Three-Leg VSC and a Transformer as Three-Phase Four-Wire DSTATCOM," IEEE Transactions on Industry Applications, vol. 47, pp. 1892-1901, 2011. 